\title{
Long-term survivors of metastatic gastric cancer for $>5$ years after chemotherapy initiation
}

\author{
Ina $\mathrm{K}^{1 *}$, Hirade $\mathrm{K}^{2}$, Kabeya $\mathrm{M}^{3}$, Kataoka $\mathrm{T}^{2}$ and Furuta $\mathrm{R}^{1}$ \\ ${ }^{1}$ Department of Medical Oncology, Nagoya Memorial Hospital, Nagoya, Japan \\ ${ }^{2}$ Department of Clinical Oncology, Nagoya Memorial Hospital, Nagoya, Japan \\ ${ }^{3}$ Department of Pharmacy, Nagoya Memorial Hospital, Nagoya, Japan
}

\begin{abstract}
Metastatic gastric cancer has a poor prognosis, and chemotherapy is recommended to patients with this disorder for palliative purposes. Overall survival in these patients is less than 2 years, despite the development of chemotherapeutic and biological agents. However, it is critical to review the survival benefits related to chemotherapy, owing to the possibility of recent progress in immunotherapy improving the prognosis of patients with gastric cancer. We have experienced 8 cases of long-term survivors of metastatic gastric cancer beyond 5 years after the initiation of chemotherapy. The characteristics of long-term survivors along with 18 cases reported in the literatures were analyzed to determine the specific factors that regulate chemosensitivity. We found that performance status should be associated with the prognosis of affected patients. Good response to systemic chemotherapy may be essential for prolonged survival of patients with distant metastases.
\end{abstract}

\section{Core tip}

We experienced eight long-term survivors of metastatic gastric cancer beyond 5 years after the initiation of chemotherapy. Literature search was conducted to determine the characteristics of chemosensitive subgroups. Good performance status was found to be associated with the prognosis of 26 long-term survivors. In patients with distant metastases, good response to systemic chemotherapy may be essential for prolonged survival. The specific factors other than performance status were still unknown.

\section{Introduction}

Immunotherapy has recently emerged as one of the most promising strategies for cancer treatment [1]. Globally, gastric cancer is the fifth most common malignancy worldwide and third leading cause of cancer-related death [2]. Chemotherapy is recommended to patients with metastatic gastric cancer for palliative purposes, considering the possibility of improving overall survival (OS) using chemotherapy compared with supportive care [3]. Despite the development of chemotherapeutic and biological agents, OS of patients with unresectable or recurrent gastric cancer remains less than 2 years $[4,5]$. Regarding immunotherapy, clinical trials are ongoing to investigate the role of immune checkpoint inhibitors in gastric cancer [6-8]. Therapeutic use of anti-PD-1 antibodies may prolong survival in patients with metastatic gastric cancer similar to those with melanoma and lung cancer $[9,10]$. Therefore, it is important to review the survival benefit in metastatic gastric cancer patients focused on chemotherapy alone.

In advanced gastric cancer, several chemotherapeutic agents including fluorouracil, platinum, and taxanes have been found to be active. The oral fluoropyrimidine anticancer agent $\mathrm{S}-1$, first developed in Japan, was designed to enhance the anticancer activity of fluorouracil in combination with two modulating substances, namely, gimeracil, which inhibits dihydropyrimidine dehydrogenase, and potassium oxonate, which reduces gastrointestinal toxicity [11]. The antitumor effect of fluoropyrimidine is enhanced by the biochemical modulation of folate metabolism modified by cisplatin, and combination therapy using S-1 and cisplatin has been shown to achieve high response rates $[12,13]$. In Japan, S-1 plus cisplatin is the standard therapy for advanced gastric cancer. In patients with advanced gastric cancer, a recent phase 3 clinical study reported S-1 plus oxaliplatin to be as effective as S-1 plus cisplatin [14], whereas oxaliplatin combined with S-1 plus leucovorin has been demonstrated to be more active than S-1 plus cisplatin [15]. In addition, taxane derivatives such as docetaxel and paclitaxel have a unique mechanism of action that differs from those of fluoropyrimidines and platinum compounds $[16,17]$.

Stage 4 gastric cancer patients with para-aortic or Virchow's node involvement alone showed a good prognosis compared with those with metastases at other sites $[18,19]$. In general, patients with liver metastasis have a very poor prognosis; however, curative resection of primary and metastatic hepatic lesions has resulted in a 5-year survival rate of $11 \%-42 \%$ [20-25]. Exclusion of patients with para-aortic or Virchow's node involvement leaves very few long-term survivors of metastatic gastric cancer beyond 5 years after the initiation of chemotherapy [26]. We at first examined such long-term survivors in our hospital and then performed the literature search to determine the chemosensitive subgroups of patients with metastatic gastric cancer.

*Correspondence to: Kenji Ina, MD, PhD, Department of Medical Oncology, Nagoya Memorial Hospital, 4-305 Hirabari, Tenpaku-ku, Nagoya, 468-8520, Japan, E-mail: kina@hospy.or.jp

Key words: gastric cancer, long-term survivors, chemotherapy, complete response

Received: April 05, 2019; Accepted: May 01, 2019; Published: May 03, 2019 


\section{Methods}

Medical records were retrospectively reviewed to examine the clinicopathological features of metastatic gastric cancer patients receiving chemotherapy in Nagoya Memorial Hospital. The chart review was approved by ethics committee of our hospital. We defined longterm survivors as those with survival beyond 5 years after the initiation of systemic chemotherapy. Objective response to chemotherapy was evaluated using the criteria proposed by the Japanese Research Society for Gastric Cancer [27] for primary lesions using gastroscopy or barium gastrography or Response Evaluation Criteria in Solid Tumors [28] for metastatic lesions. Complete response (CR) was defined as the disappearance of all evidence related to cancer for at least 4 weeks. Response Evaluation Criteria in Solid Tumors has defined partial response (PR) as $>50 \%$ reduction in tumor volume. Progressive disease was defined as a new lesion or enlargement exceeding the original tumor size by $25 \%$. Patients not belonging to these categories were considered to have a stable disease (SD). OS was calculated from the initiation of chemotherapy to death or the most recent follow-up day.

A systematic literature search using PubMed was conducted using the terms of "gastric cancer," "long-term survival," and "chemotherapy." Data were collected from the manuscripts for age at the time of the initiation of chemotherapy, sex, performance status (PS), macroscopic findings, histological type, TNM classification, ascites, history of gastrectomy including curative or palliative surgery, metastatic sites, serum alkaline phosphatase (ALP) levels at baseline, serum carcinoembryonic antigen levels at baseline, chemotherapy regimens, tumor response, history of conversion surgery, and OS. Patients treated with immune checkpoint inhibitors were excluded from the present analysis to determine the chemosensitive subgroups of stage 4 gastric cancer patients. Because the data for PS, macroscopic findings, TNM classification, ascites, ALP levels, and serum carcinoembryonic antigen levels were missing for some cases, the following factors were analyzed by converting these variables into dichotomous variables; (1) age, $<65$ vs > 65 years; (2) male vs female; (3) histological type, intestinal type (I) vs diffuse type (D); (4) number of metastatic sites, 1 vs 2 or more; (5) history of gastrectomy prior to chemotherapy; and (6) curative vs palliative surgery. OS curves of long-term survivors were estimated using the Kaplan-Meier analysis and compared using the log-rank test for statistical analysis. Differences with P-values $<0.05$ were considered statistically significant. All statistical analyses were performed using EZR (Saitama Medical Center, Jichi Medical University; http://www. jichi.ac.jp/ saitama-sct/SaitamaHP.files/statmedEN.html), which is a graphical user interface for $\mathrm{R}$ (The R Foundation for Statistical Computing, Vienna, Austria) [29].

\section{Results}

After excluding patients with isolated either para-aortic or left cervical lymph node involvement, those who underwent curative resection of primary gastric cancer and liver metastasis, and those treated with immune checkpoint inhibitors, there were eight longterm survivors of metastatic gastric cancer for more than 5 years after the initiation of chemotherapy in Nagoya Memorial Hospital. The chemotherapeutic responses of eight survivors were CR $(n=4), P R(n=1)$, and SD ( $n=3)$; objective response rates (ORRs) was $62.5 \%(5 / 8)$. Next, there were no long term-survivors with poor PS, i.e., $>3$. Figure 1 showed the chronological images of case 1 with recurrent lung metastasis after curative gastrectomy; a single metastatic lesion completely disappeared in response to chemotherapy. Case 2 displayed extensive lymph node involvement and single hepatic metastasis and underwent conversion surgery after chemotherapy, achieving confirmed pathological CR [30]. Case 3 showed severe peritoneal metastasis; therefore, an exploratory laparotomy was performed and palliative chemotherapy was initiated; this patient showed an excellent response to S-1-based chemotherapy and eventually underwent curative surgery 2 years later, yielding pathological CR [30]. Complete disappearance of the primary gastric lesion and multiple liver metastases was revealed in case 4 (Figure 2) [31]. The outcome of our long-term survivors showed that seven cases were free from disease after the cessation of chemotherapy, indicating that palliative chemotherapy can cure metastatic gastric cancer.

And then the literature search from 2000 was conducted, in which 18 cases of long term survivors have been found [32-41]. The characteristics of 26 long-term survivors, including our 8 cases, are summarized in Table 1 . The patients comprised 18 males and 8 females aged 48-81 years. PS grade was well maintained in every long-term survivors described in the manuscripts. Aside from lymph nodes, the peritoneum was noted to be the most common metastatic sites $(n=17)$, followed by the liver $(n=6)$ and lung $(n=3)$. Among 17 cases with peritoneal involvement, primary gastric lesions were resected in 14 cases (eight curative and six palliative) prior to chemotherapy. Five long-term survivors had multiple liver metastases, all of whom showed a good response to systemic chemotherapy (CR 3, PR 2). Three cases with lung metastases showed CR. It is noted that 11 patients with huge amounts of tumor were cured in response to palliative chemotherapy, although previous reports described that gastric cancer patients with small burden of tumor showed better survival than the others [26,33] (Table 1). On the other hand, long-term survivors showing SD had peritoneal metastasis without liver or lung metastasis. Our findings implicated that prolonged survival of gastric cancer patients with distant metastases should necessitate patients to be chemosensitive.

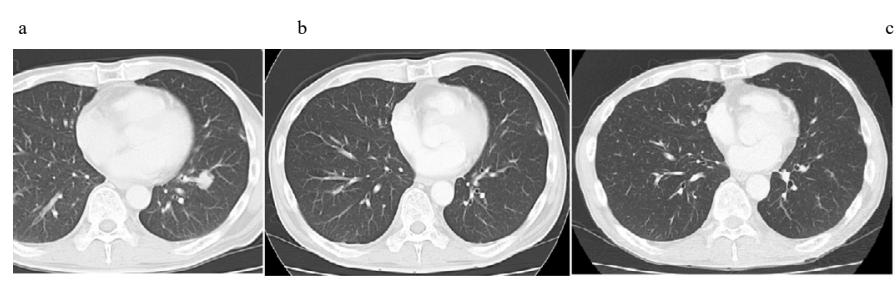

Figure 1. Chronological images of case 1

a. Computed tomography (CT) scans demonstrated a single mass in the lung prior to chemotherapy.

b. Complete disppearance of lung metastasis was observed after 2 cycles of S-1/cisplatin plus paclitaxel.

c. There were no recurrence five years after the cessation of chemotherapy. He then suffered from small cell lung carcinoma, underwent curative surgery, and is still alive
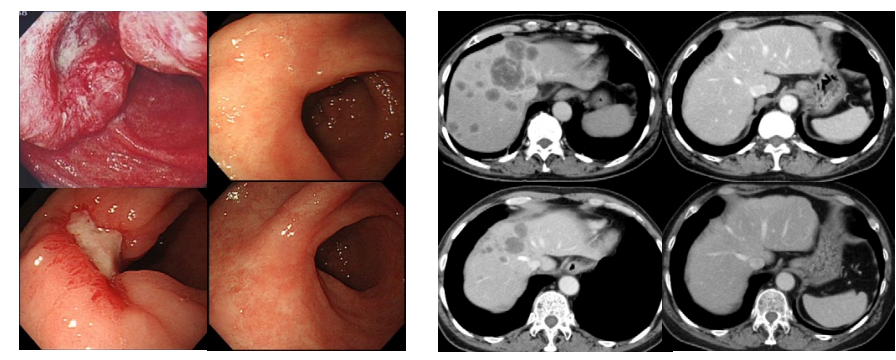

Figure 2. Chronological images of case 4

Complete disppearance of the primary gastric lesion and multiple liver metastases was demonstrated after 6 cycles of S-1/cisplatin plus paclitaxel and S-1 monotherapy (Complete response : CR). This patients has been free from disease five years after the cessation of chemotherapy. This case was previously presented in part in the reference of 31 
Prognosis of patients with metastatic gastric cancer was categorized as good, moderate, or poor risk using the following factors; number of metastatic sites, ALP levels, and PS grade [36]. At least our three patients (cases 2, 3, and 4) were categorized as poorrisk among the 26 long-term survivors. Moreover, some individuals had multiple metastatic sites $(\mathrm{n}=11)$, and elevated ALP levels (cases 4 and 6), or exhibited PS 2 (cases 2 and 3). Notably, there were no longterm survivors with poor PS, i.e., $>3$. The therapeutic regimens that attained CR included S-1 alone $(n=2)$, capecitabine/cisplatin $(n=2)$, S-1/cisplatin $(n=6)$, fluorouracil/ cisplatin $(n=1)$, and S-1/cisplatin plus paclitaxel $(n=2)$. Histological type and number of metastatic sites did not demonstrate a close relationship with prognosis (Figure 3) similar to age, sex, and history of gastrectomy. In 20 long-term survivors whose primary gastric lesions were resected, the OS curves of those who underwent palliative surgery $(n=7)$ did not differ from the curves of those who underwent curative surgery $(\mathrm{n}=13)$ (Figure 4).
In addition, the literature search revealed several other CR cases of metastatic gastric cancer, most of whom did not receive long-term follow-up. The majority of these cases were reported in Japan [42-45], with only a few cases described in other countries $[46,47]$. The present analysis selected cases that could be traced more than 5 years after the initiation of chemotherapy. As a result, all of long-term survivors were Japanese patients, which could have been biased including institutional disparities and ethnic factors.

\section{Conclusion}

We experienced eight long-term survivors of metastatic gastric cancer. A literature search was then conducted to identify the characteristics of long-term survivors receiving chemotherapy. The analysis of 26 long-term survivors showed PS grade to be associated with good prognosis of metastatic gastric cancer patients. Furthermore, good response to systemic chemotherapy may be essential for prolonged survival in patients with distant metastases.

Table 1. Characteristics of 26 long-term survivors of metastatic gastric cancer for more than 5 years after the initiation of chemotherapy since 2000

\begin{tabular}{|c|c|c|c|c|c|c|c|c|c|c|c|c|c|c|c|c|c|c|c|}
\hline \multirow{3}{*}{\begin{tabular}{c|} 
Case \\
1 \\
2
\end{tabular}} & \multirow{3}{*}{\begin{tabular}{|c|} 
Ref. \\
NP \\
30 \\
\end{tabular}} & \multirow{3}{*}{\begin{tabular}{c|} 
Age \\
63 \\
53 \\
\end{tabular}} & \multirow{3}{*}{$\begin{array}{c}\text { Gender } \\
\mathrm{M} \\
\mathrm{M} \\
\end{array}$} & \multirow{3}{*}{$\begin{array}{c}\text { Macroscopic } \\
\text { findings }\end{array}$} & \multicolumn{2}{|c|}{$\begin{array}{l}\text { Histological } \\
\text { type }\end{array}$} & \multirow{2}{*}{\multicolumn{3}{|c|}{\begin{tabular}{|l|l|l|}
$\mathbf{T}$ & $\mathbf{N}$ & $\mathbf{M}$ \\
\end{tabular}}} & \multirow{3}{*}{\begin{tabular}{|c|}
$\begin{array}{c}\text { Metastatic } \\
\text { sites }\end{array}$ \\
lung \\
liver, \\
peritoneum, \\
LN \\
\end{tabular}} & \multirow{3}{*}{\begin{tabular}{|c|}
$\begin{array}{c}\text { No of } \\
\text { metastasis }\end{array}$ \\
single \\
multiple \\
\end{tabular}} & \multirow{3}{*}{$\begin{array}{c}\text { Primary } \\
\text { resection }\end{array}$} & \multirow{3}{*}{\begin{tabular}{r|}
$\begin{array}{c}\text { 1st } \\
\text { line }\end{array}$ \\
PSC \\
SP
\end{tabular}} & \multirow{3}{*}{\begin{tabular}{|c|} 
2nd line \\
S-1 \\
S-1 \\
\end{tabular}} & \multirow{3}{*}{$\begin{array}{c}\text { 3rd line } \\
\text { none } \\
\text { none }\end{array}$} & \multirow{3}{*}{\begin{tabular}{|c|} 
Response \\
$\mathrm{CR}$ \\
$\mathrm{CR}$ \\
\end{tabular}} & \multirow{3}{*}{$\begin{array}{c}\begin{array}{c}\text { Survival } \\
\text { (Mo) }\end{array} \\
152 \\
118\end{array}$} & \multirow{3}{*}{\begin{tabular}{|c|} 
PS \\
1 \\
2
\end{tabular}} & \multirow{3}{*}{\begin{tabular}{|c|} 
Ascites \\
none \\
none
\end{tabular}} \\
\hline & & & & & \multirow{2}{*}{$\begin{array}{l}\text { well } \\
\text { por }\end{array}$} & \multirow{2}{*}{$\begin{array}{l}\mathrm{I} \\
\mathrm{D}\end{array}$} & & & & & & & & & & & & & \\
\hline & & & & & & & $\mathrm{T} 4$ & N3 1 & M1 & & & & & & & & & & \\
\hline 3 & 30 & 62 & M & non & $\bmod$ & $\mathrm{D}$ & T3 1 & NX 1 & M1 & $\begin{array}{l}\text { peritoneum, } \\
\text { LN }\end{array}$ & multiple & - & $\mathrm{SP}$ & S-1 & none & $\mathrm{CR}$ & 200 & 1 & none \\
\hline 4 & 31 & 65 & M & non & well & I & T3 & N3 1 & M1 & liver, $\mathrm{LN}$ & multiple & - & PSC & S-1 & none & $\mathrm{CR}$ & 101 & 2 & none \\
\hline 5 & NP & 71 & M & non & $\bmod$ & $\mathrm{D}$ & Rec & curren & nce & peritoneum & single & curative & $\begin{array}{l}\text { S-1/ } \\
\text { PTX }\end{array}$ & S-1 & none & SD & 168 & 1 & none \\
\hline 6 & NP & 51 & $\mathrm{~F}$ & scirrhous & por & $\mathrm{D}$ & $\mathrm{T} 4$ & N1 1 & M1 & peritoneum & single & palliative & $\mathrm{SP}$ & $\begin{array}{l}\text { 5-FUDR/ } \\
\text { DOC }\end{array}$ & UFT & SD & 170 & 1 & + \\
\hline 7 & NP & 77 & M & scirrhous & sig & $\mathrm{D}$ & Rec & curren & nce & peritoneum & single & curative & $\mathrm{SP}$ & S-1 & none & SD & 109 & 1 & none \\
\hline 8 & NP & 60 & M & non & $\bmod$ & $\mathrm{D}$ & T4 & N3 1 & M1 & liver, LN & multiple & - & S-1 & XP & $\mathrm{X} / \mathrm{DOC}$ & PR & 67 & 0 & none \\
\hline 9 & 32 & 81 & M & non & $\bmod$ & $\mathrm{D}$ & T3 & N1 & M1 & liver, lung & multiple & - & $\mathrm{SP}$ & S-1 & none & $\mathrm{CR}$ & 89 & ND & none \\
\hline 10 & 33 & 56 & $\mathrm{~F}$ & scirrhous & por & $\mathrm{D}$ & Rec & curren & nce & peritoneum & single & curative & S-1 & ND & ND & SD & 62 & 0 & ND \\
\hline 11 & 34 & 60 & M & non & por & $\mathrm{D}$ & Rec & curren & nce & liver, LN & multiple & curative & EAP & 5-FU/MTX & $\begin{array}{c}\mathrm{CPT} / \\
\text { cisplatin }\end{array}$ & PR & 60 & ND & none \\
\hline 12 & 35 & 55 & $\mathrm{~F}$ & ND & por & $\mathrm{D}$ & & ND & & peritoneum & single & palliative & $\mathrm{SP}$ & ND & ND & $\mathrm{CR}$ & 81 & 0 & ND \\
\hline 13 & 36 & 63 & M & ND & por & $\mathrm{D}$ & & ND & & peritoneum & single & - & $\mathrm{SP}$ & ND & ND & SD & 60 & 1 & ND \\
\hline 14 & 36 & 51 & M & ND & por & $\mathrm{D}$ & & ND & & $\begin{array}{l}\text { peritoneum, } \\
\text { LN }\end{array}$ & multiple & palliative & XP & ND & ND & $\mathrm{CR}$ & 64 & 0 & ND \\
\hline 15 & 36 & 48 & $\mathrm{~F}$ & ND & por & $\mathrm{D}$ & & ND & & peritoneum & single & palliative & S-1 & ND & ND & SD & 65 & 0 & ND \\
\hline 16 & 36 & 54 & $\mathrm{~F}$ & ND & por & $\mathrm{D}$ & & ND & & peritoneum & single & curative & PTX & ND & ND & SD & 69 & 1 & ND \\
\hline 17 & 36 & 71 & M & ND & well & I & & ND & & lung, LN & multiple & curative & $\mathrm{XP}$ & ND & ND & $\mathrm{CR}$ & 71 & 0 & ND \\
\hline 18 & 36 & 65 & $\mathrm{~F}$ & ND & por & $\mathrm{D}$ & & ND & & peritoneum & single & palliative & PTX & ND & ND & SD & 77 & 0 & ND \\
\hline 19 & 36 & 58 & M & ND & well & I & & ND & & peritoneum & single & curative & S-1 & ND & ND & SD & 80 & 1 & ND \\
\hline 20 & 36 & 59 & $\mathrm{M}$ & ND & por & $\mathrm{D}$ & & ND & & peritoneum & single & curative & FL & ND & ND & SD & 96 & 1 & ND \\
\hline 21 & 36 & 64 & M & ND & por & $\mathrm{D}$ & & ND & & peritoneum & single & curative & S-1 & ND & ND & $\mathrm{SD}$ & 117 & 0 & ND \\
\hline 22 & 37 & 80 & M & non & $\bmod$ & $\mathrm{D}$ & Rec & curren & nce & peritoneum & single & curative & S-1 & ND & ND & $\mathrm{CR}$ & 66 & ND & none \\
\hline 23 & 38 & 69 & M & non & por & $\mathrm{D}$ & $\mathrm{T} 2$ & N2 1 & M1 & liver & multiple & palliative & SP & ND & ND & $\mathrm{CR}$ & 87 & ND & none \\
\hline 24 & 39 & 61 & $\mathrm{~F}$ & non & $\bmod$ & $\mathrm{D}$ & T3 & N3 1 & M1 & LNs & multiple & curative & SP & ND & ND & $\mathrm{CR}$ & 60 & ND & none \\
\hline 25 & 40 & 58 & M & non & well & I & Rec & curren & nce & peritoneum & single & palliative & FP & S-1 & none & $\mathrm{CR}$ & 72 & ND & none \\
\hline 26 & 41 & 55 & $\mathrm{~F}$ & non & por & $\mathrm{D}$ & Rec & curren & nce & LNs & multiple & curative & S-1 & none & none & $\mathrm{CR}$ & 140 & ND & none \\
\hline
\end{tabular}

NP: not published; non: non-scirrhous; LN: lymph nodes; SP: S-1 plus cisplatin; EAP: etoposide/ adriamycin/ cisplatin; XP: capecitabine plus cisplatin; PTX: paclitaxel; FL: 5-FU plus leucovorin; FP: 5-FU plus cisplatin; PSC: paclitaxel/ S-1/ cisplatin; MTX: methotrexate; DOC: docetaxel; X: capecitabine; CR: complete response; PR: partial response; SD: stable disease; PS: performance status; ND: not described 
(A)

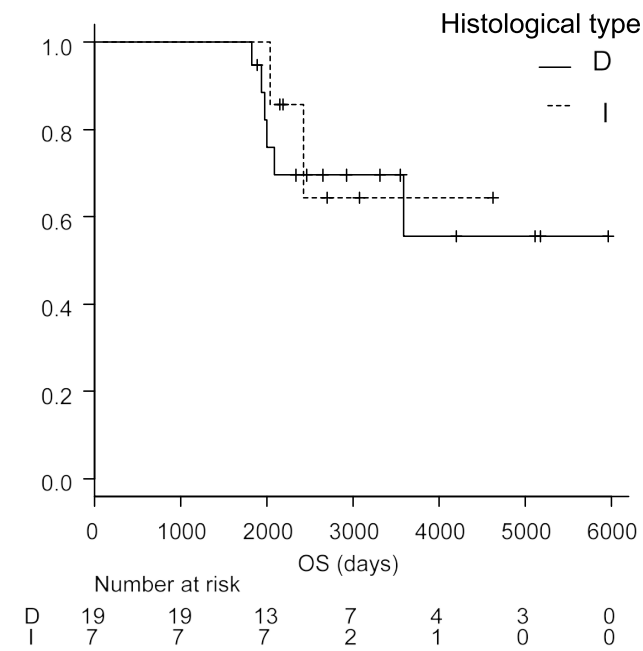

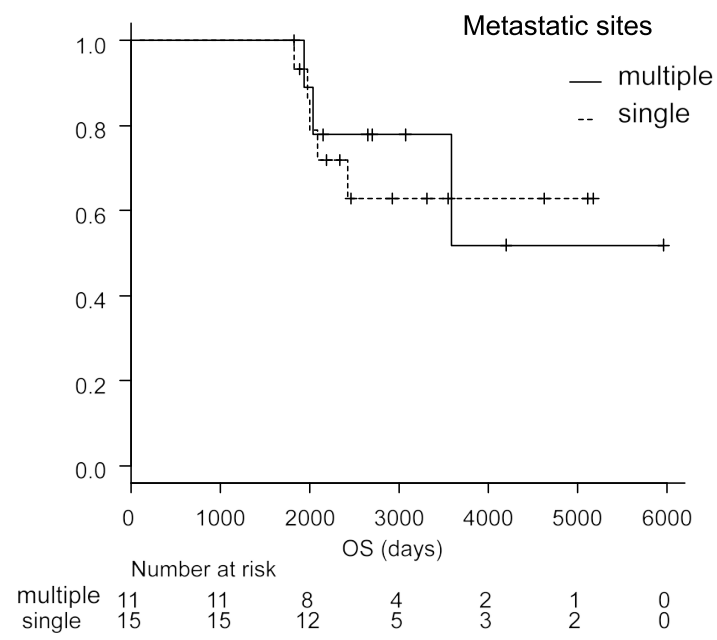

Figure 3. Kaplan-Meier curves of overall survival (OS) in 26 long-term survivors beyond 5 years after the initiation of chemotherapy a. Histological type, intestinal type (I) vs diffuse type (D)

b. Number of metastatic sites, 1 (single) vs 2 or more (multiple)

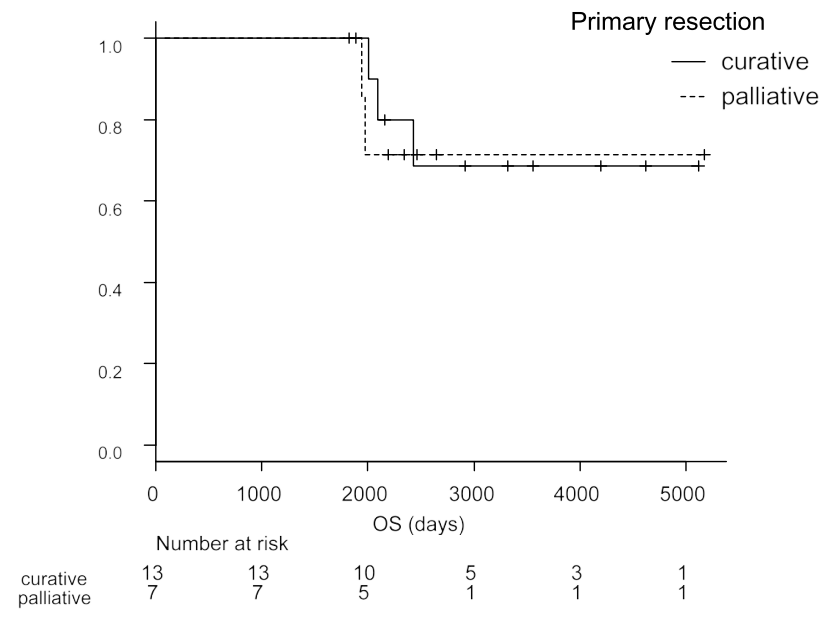

Figure 4. Kaplan-Meier curves of overall survival (OS) in 20 long-term survivors whose primary gastric lesions were resected. We compared OS between cases receiving curative surgery $(\mathrm{n}=13)$ and palliative resection $(\mathrm{n}=7)$, which did not show any differences

\section{Acknowledgement}

The authors are very grateful to Drs. Shoji Suga and Hiroaki Iwase for their precious instruction.

\section{Conflicts of interest}

The authors have no potential conflicts of interest to declare.

\section{References}

1. Sharma P, Allison JP (2015) Immune checkpoint targeting in cancer therapy: Toward combination strategies with curative potential. Cell 161: 205-2014. [Crossref]

2. International Agency for Research on Cancer. GLOBOCAN 2018: estimated cancer incidence, mortality and prevalence worldwide. Available online: http://globocan.iarc. fr/Default.aspx (accessed on 31 January 2019).

3. Glimelius B, Ekstrom K, Hoffman K, Graf W, Sjoden PO, et al. (1997) Randomized comparison between chemotherapy plus best supportive care with best supportive care in advanced gastric cancer. Ann Oncol 8: 163-168. [Crossref]
4. Hohenberger P, Gretschel S (2003) Gastric cancer. Lancet 362: 305-315. [Crossref]

5. Bang Y, Van Custem E, Feyereislova A, Chung HC, Shen L, et al. (2010) Trastuzumab in combination with chemotherapy versus chemotherapy alone for treatment of HER2positive advanced gastric or gastro-oesophageal junction cancer (ToGA): a phase 3, open-label, randomised controlled trial. Lancet 28: 687-697. [Crossref]

6. Kang YK, Boku N, Satoh T, Ryu MH, Chao Y, et al. (2017) Nivolumab in patients with advanced gastric or gastro-oesophageal junction cancer refractory to, or intolerant of, at least two previous chemotherapy regimens (ATTRCTION-2): a randomised, doubleblind, placebo-controlled, phase 3 trial. Lancet 390: 2461-2471. [Crossref]

7. Muro K, Chung HC, Shankaran V, Geva R, Catenacci D, Gupta S, et al. (2016) Pembrolizumab for patients with PD-L1-positive advanced gastric cancer (KEYNOTE-012): A multicentre, open-label, phase 1b trial. Lancet Oncol 17: 717726. [Crossref]

8. Boku N, Ryu MH, Kato K, Chung HC, Minashi K, et al. (2019) Safety and efficacy of nivolumab in combination with S-1/ capecitabine plus oxaliplatin in patients with previously untreated, unresectable, advanced, or recurrent gastric/ gastroesophageal junction cancer: Interim results of a randomized, phase II trial (ATTRACTION-4). Ann Oncol 30: 250-258. [Crossref] 
9. Larkin J, Chiarion-Sileni V, Gonzalez R, Grob JJ, Cowey CL, et al. (2015) Combined nivolumab and ipilimumab or monotherapy in untreated melanoma. N Engl J Med 373 : 23-34.

10. Borghaei H, Paz-Ares L, Horn L, Spigel DR, Steins M, et al. (2015) Nivolumab versus docetaxel in advanced nonsquamous non-small-cell lung cancer. $N$ Engl J Med 373: 1627-1639. [Crossref]

11. Shirasaka T, Shimamoto Y, Ohshino H (1996) Development of a novel form of an oral 5-fluorouracil derivative (S1) directed to the potentiation of the tumour selective cytotoxicity of 5-5-fluorouracil by two biochemical modulations. Anticancer Drugs 7: 548-557. [Crossref]

12. Lenz HJ, Lee FC, Haller DG, Singh D, Benson AB, et al. (2007) Extended safety and efficacy data on S-1 plus cisplatin in patients with untreated, advanced gastric carcinoma in a multi-centre phase II study. Cancer 9: 33-40. [Crossref]

13. Koizumi W, Narahara H, Hara T, Takagane A, Akiya T, et al. (2008) S-1 plus cisplatin versus S-1 alone for first line treatment of advanced gastric cancer (SPIRITS trial): A phase III trial. Lancet Oncol 9: 215-221. [Crossref]

14. Yamada Y, Higuchi K, Nishikawa K (2015) Phase 3 study comparing oxaliplatin plus S-1 with cisplatin plus S-1 in chemotherapy-naïve patients with advanced gastric cancer. Ann Oncol 26: 141-148. [Crossref]

15. Hironaka S, Sugimoto N, Yamaguchi K, Moriwaki T, Komatsu Y, et al. (2016) S-1 plus cisplatin leucovorin versus S-1 plus leucovorin and oxaliplatin versus S-1 plus cisplatin in patients with advanced gastric cancer: a randomized, multi centre, open-label, phase 2 trial. Lancet Oncol 17: 99-108. [Crossref]

16. Ohtsu A, Boku N, Tamura F, Muro K, Shimada Y, et al. (1998) An early phase II study of a 3-hour infusion of paclitaxel for advanced gastric cancer. Am J Clin Oncol 21: 416-419. [Crossref]

17. Iwase H, Shimada M, Tsuzuki T, Ina K, Sugihara M, et al. (2011) A phase 2 multi-study of triple therapy with paclitaxel, S-1, and cisplatin in patients with advanced gastric cancer. Oncology 80: 76-83. [Crossref]

18. Park IH, Kim SY, Kim YW, Ryu KW, Lee JH, et al. (2011) Clinical characteristics and treatment outcomes of gastric cancer patients with isolated para-aortic lymph node involvement. Cancer Chemother Pharmacol 67: 127-136.

19. Hirai K, Takeyoshi I, Kawate S, Sunose Y, Yoshinari D, et al. (2010) A case of gastric cancer with Virchow and para-aortic node metastases treated successfully using S-1. Jpn J Cancer Chemother 37: 517-520.

20. Miki Y, Fujitani K, Hirao M, Kurokawa Y, Mano M, et al. (2012) Significance of surgical treatment of liver metastasis from gastric cancer. Anticancer Res 32: 665-670.

21. Wang YN, Shen KT, Ling JQ, Gao XD, Hou YY, et al. (2012) Prognostic analysis of combined resection of the stomach and liver lesions in 30 gastric cancer patients with synchronous liver metastasis. BMC Surg 12: 20-26.

22. Schildberg CW, Croner R, Merkel S, Schellerer V, Muller V, et al. (2012) Outcome of operative therapy of hepatic metastatic stomach carcinoma: A retrospective analysis. World J Surg 36: 872-878.

23. Kodera Y, Fujitani K, Fukushima N, Ito S, Muro K, et al. (2014) Surgical resection of hepatic metastasis from gastric cancer: a review and new recommendation in the Japanese gastric cancer treatment guidelines. Gastric Cancer 17: 206-212. [Crossref]

24. Oki E, Tokunaga S, Emi Y, Kusumoto T, Yamamoto M, et al. (2016) Surgical treatment of liver metastasis of gastric cancer: a retrospective multicentre cohort study (KSCC1302). Gastric Cancer 19: 968-976. [Crossref]

25. Tiberio GAM, Ministrini S, Gardini A, Marrelli D, Marchet A, et al. (2016) Factors influencing survival after hepatectomy for metastases from gastric cancer. EJSO 42: 1229-1235. [Crossref]

26. Yoshida M, Ohtsu A, Boku N, Miyata Y, Shirao K, et al. (2004) Long-term survival and prognostic factors in patients with metastatic gastric cancer treated with chemotherapy in the Japan Clinical Oncology Group (JCOG) study. Jpn J Clin Oncol 34: 654-659. [Crossref]

27. Japnese Gastric Cancer Association (2017) Japanese gastric cancer treatment guidelines 2014 ver.4. Gastric Cancer 20: 1-9. [Crossref]

28. Therasse P, Arbuck SG, Eisenhauer EA, Wanders J, Kaplan RS, et al. (2000) New guidelines to evaluate the response to treatment in solid tumours. European Organization for research and treatment of cancer, National Cancer Institute of the United States, National Cancer Institute of Canada. J Natl Cancer Inst 92: 205-216. [Crossref]

29. Kanda Y (2013) Investigation of the freely available easy-to-use software 'EZR' for medical statistics. Bone Marrow Transplant 48: 452-458. [Crossref]
30. Ina K, Kataoka T, Takeuchi Y, Fukuoka T, Miwa T, et al. (2008) Pathological complete response induced by combination therapy of S-1 and 24-hour infusion of cisplatin in two cases initially diagnosed as inoperable highly advanced gastric cancer. Oncol Rep 20: 259-264.

31. Ina K, Furuta R (2017) Image of Month: Complete response of metastatic gastric cancer to chemo-immunotherapy. Indian J Med Res 146: 141.

32. Kanagawa T, Maruki Y, Nagoya H, Kosugai Y, Akimoto T, et al. (2016) Clinical complete response from chemotherapy in an elderly patients with metastatic gastric cancer: A case report. J Nippon Med Sch 83: 199-202. [Crossref]

33. Hosokawa A, Sugiyama T, Ohtsu A, Doi T, Hattori S, et al. (2007) Long-term outcomes of patients with metastatic gastric cancer after initial S-1 monotherapy. $J$ Gastroentero/ 42: 533-538. [Crossref]

34. Saitoh H, Boku N, Ohtsu A, Hironaka S, Miyamoto S, et al. (2000) Five-yea survivor with liver metastasis from gastric cancer successfully treated with systemic chemotherapy. Gastric Cancer 3: 106-109. [Crossref]

35. Kadowaki S, Komori A, Narita Y, Nitta S, Yamaguchi K, et al. (2014) Long-term outcomes and prognostic factors of patients with advanced gastric cancer treated with $\mathrm{S}-1$ plus cisplatin combination chemotherapy as a first-line treatment. Int J Clin Oncol 19: 656-661. [Crossref]

36. Kadowaki S, Komori A, Takahari D, Ura T, Ito S, et al. (2015) Clinical characteristics associated with long-term survival in metastatic gastric cancer after systemic chemotherapy. Asian Pac J Cancer Prev 16: 5433-5438. [Crossref]

37. Kusama T, Yamagami K, Hasegawa M, Sone N, Kokado Y, et al. (2016) An elderly patient with local recurrence of gastric cancer responding completely to S-1 monotherapy. Jpn J Cancer Chemother 43: 247-250.

38. Okada K, Oka Y, Nagata H, Yoshioka S, Ueshima S, et al. (2016) A case of successful treatment of liver metastases from gastric cancer with chemotherapy. Jpn J Cancer Chemother 43: 2386-2388. [Crossref]

39. Kanagawa T, Ohkuwa T, Nogami H, Kobatake T (2013) A case of gastric cance with Virchow and para-aortic node metastasis treated successfully by neo-adjuvant chemotherapy with S-1/ CDDP. Jpn J Cancer Chemother 40: 1217-1220. [Crossref]

40. Okuda N, Takahashi K, Yagi Y, Ichikawa K, Yamaoka T, et al. (2007) Prolonged complete response obtained by single agent S-1 in a case of peritoneal metastasis from gastric remnant cancer. Jpn J Cancer Chemother 34: 1659-1661.

41. Nishikawa K, Kawada J, Fujitani K, Fushimi H, Endo S, et al. (2015) A case of recurrent gastric cancer with left cervical lymph node and para-aortic lymph node successfully treated with TS-1 chemotherapy. Jpn J Cancer Chemother 42: 2075-2077. [Crossref]

42. Iwase H, Kaida S, Nakamura M, Mizuno T, Iyo T, et al. (2001) Complete response in a case of advanced gastric cancer with liver and intra-abdominal lymph node metastases treated by combined chemotherapy of TS-1 and CDDP. Jpn J Cancer Chemother 28: 1441-1444. [Crossref]

43. Ishido K, Koizumi W, Tanabe S, Higuchi K, Sasaki T, et al. (2008) A patient with stage 4 type 4 advanced gastric cancer who had a complete pathological response to shortterm treatment with S-1 alone. Anti-Cancer Drugs 19: 921-925. [Crossref]

44. Iwakura S, Shimamoto T, Higasiguchi T, Nakase T, Shimada K, et al. (2012) A case of gastric cancer with peritoneal dissemination and massive ascites successfully treated with S-1/ docetaxel therapy. Jpn J Cancer Chemother 39: 1251-1253. [Crossref]

45. Koike M, Mino K, Shoji H, Konishi Y, Katayama T, et al. (2014) A case of complete response to multiple liver metastasis of gastric cancer after discontinuation of S-1 administration. Jpn J Cancer Chemother 41: 893-896. [Crossref]

46. Tetzlaff ED, Faust J, Ajani JA (2006) Long term survival of a western patient with metastatic gastric cancer treated with S-1 plus cisplatin. Gastric Cancer 9: 140-143. [Crossref]

47. Teker F, Canbaz F, Kemal Y, Yucel I (2015) A case of gastric cancer with liver metastases had a complete response with cisplatin and capecitabine as third-line chemotherapy. $J$ Cancer Res Ther 11: 1026. [Crossref]

Copyright: (C2019 Ina K. This is an open-access article distributed under the terms of the Creative Commons Attribution License, which permits unrestricted use, distribution, and reproduction in any medium, provided the original author and source are credited. 